\title{
Perceived Social Support among Mentally Ill Patients
}

\author{
Bandana Pokharel, ${ }^{\mathrm{a}, \mathrm{c}}$ Anupama Pokharel $\mathrm{b}^{\mathrm{b}, \mathrm{c}}$
}

\begin{abstract}
:
Introduction: Social support is the perception that one is cared for, has assistance available from significant others and its benefit is by buffering stress by influencing the ability to adjust and live with illness. Social support can uplift the quality and subjective wellbeing of people. The objective of this study was to examine the perceived social support and factors influencing it among mentally ill patients. Methods: A descriptive cross-sectional study was carried out. Ninety cases aged more than 18 years visiting outpatient of psychiatric department and diagnosed as a case of mental illness for at least a year were included. Instruments used were self-developed proforma and Multidimensional Scale of Perceived Social Support. Interview technique was used to collect the data. Results: Majority (60\%) of the patients perceive social support from family, $28 \%$ of the patients perceive social support from significant others. Regression analysis showed that the perceived social support is influenced by employment status, type of family one lives in and physical illness. It is not influenced by gender, subjective financial status and frequency of hospitalization. Conclusion: Perceived social support is influenced by employment status, type of family one lives in and physical illness. Majority $(60 \%)$ of the patients perceive social support from family.
\end{abstract}

Keywords: mentally ill • social support • employment • regression

\section{INTRODUCTION:}

Social support is the perception that one is cared for and has assistance available from friends and significant others. It may benefit health by buffering stress influencing affective states and/or changing behavior, and also influencing the ability to adjust and to live with illness. Social support has generally been found to promote psychological wellbeing. ${ }^{1,2}$

Over the past twenty years, there has been great interest in the role of social support as a mechanism for the maintenance of psychological

a - Lecturer,

b - Nursing Officer

c - College of Nursing, Lumbini Medical College, Palpa, Nepal

Corresponding Author:

Ms. Bandana Pokharel

e-mail: anupbandana@gmail.com

How to cite this article:

Pokharel B, Pokharel A. Perceived social support among mentally ill patients. Journal of Lumbini Medical College. 2014;2(1):14-7. doi:

10.22502/jlmc.v2i1.48. wellbeing under conditions of stress. Social support is a multifaceted construct and a review of literature indicates that the construct of social support consists of both structural and functional component. ${ }^{3,4}$

The structural component includes informal and formal support, such as an individual's social network, the size of the social network, frequency of contact with members of the network, reciprocal support and quality of the support. ${ }^{4}$ Functional support refers to the perceived level of the support received, such as emotional support, affirmative support and tangible support. ${ }^{5}$

Social support has a major role to play in the long term course and outcome of any chronic illness. Social support from the key caregivers, environment and community can play a positive role by enabling a person with chronic disorder. Positive functional social network can work as a buffering agent. ${ }^{6}$ This way social support can uplift the quality and subjective wellbeing of people as well as enable people to develop and use positive forms of coping and problem solving strategies. ${ }^{7}$ There is a lack of study on perceived social support of mentally ill 
patients. This study was done with the objective to assess the level of perceived social support among mentally ill patients.

\section{METHODS:}

It is a cross-sectional study done from $1^{\text {st }}$ January 2014 to $30^{\text {th }}$ March 2014 in outpatient of psychiatric department at Lumbini Medical College. A purposive sampling technique was adopted for the study.

Patients with a history of mental illness for at least one year and age more than 18 years were included in the study. Patient who had significant physical illness during the time of study, patients under addiction problems of any substances and patients not willing to participate were excluded from the study. Sociodemographic profile and a valid tool of Multidimensional Scale of Perceived Social Support (A 12 item with 7 point scale related to significant others, family, friends) were used as data collection instruments. Each of the 3 areas had 4 subscales. Items were measured on 7 point Likert type scale from 1 'very strongly disagree' to 7 'very strongly agree. Scores were derived by summing the individual items and dividing by the number of items.

Data was collected by Interview using selfdeveloped proforma and perceived social support scale. All the data was collected and entered in Microsoft Excel 2013 then imported to SPSS 21. Descriptive and inferential statistics as well as regression analysis was done to find out the relationship between selected demographic variables and perceived social support.

\section{RESULTS:}

Demographic characteristics of participants is presented in Table 1 . Majority $(60 \%)$ of the patients perceived social support from their family, $28 \%$ from significant others and the rest $12 \%$ from friends. Mean score of perceived social support was $3.33(S D=1.37)$. The mean score for all individuals and each sex is shown in Table 2. It shows that the difference in score in male and female is not statistically significant.

Regression analysis was done by stepwise method to describe the relationship between the dependent variable (social support score) and the independent variables. The independent variables were sex (male, female), type of family (nuclear, joint), number of admissions (two or less, more
Table 1: Demographic characteristics of the participants $(N=90)$

\begin{tabular}{|c|c|c|c|}
\hline Variables & & $\mathbf{n}$ & $\%$ \\
\hline \multirow{5}{*}{ Cast } & Brahmin/Chhetri & 37 & 41.1 \\
\hline & Janjati & 23 & 25.6 \\
\hline & Dalit & 20 & 22.2 \\
\hline & Madeshi & 3 & 3.3 \\
\hline & Muslim & 7 & 7.8 \\
\hline \multirow{2}{*}{ Sex } & Female & 51 & 56.7 \\
\hline & Male & 39 & 43.3 \\
\hline \multirow{3}{*}{ Age } & $\leq 20$ & 8 & 8.9 \\
\hline & $21-40$ & 52 & 57.8 \\
\hline & $41-60$ & 30 & 33.3 \\
\hline \multirow{4}{*}{ Education } & Below SLC & 29 & 32.2 \\
\hline & Plus two & 13 & 14.4 \\
\hline & Illiterate & 30 & 33.3 \\
\hline & Literate & 18 & 20.0 \\
\hline \multirow{2}{*}{ Occupation } & Employed & 58 & 63.7 \\
\hline & Unemployed & 32 & 35.2 \\
\hline \multirow{2}{*}{ Family type } & Nuclear & 50 & 55.6 \\
\hline & Joint & 40 & 44.4 \\
\hline \multirow{4}{*}{ Diagnosis } & Depression & 48 & 53.3 \\
\hline & Anxiety disorder & 26 & 28.9 \\
\hline & ADSD & 13 & 14.4 \\
\hline & Dissociative Disorder & 3 & 3.3 \\
\hline
\end{tabular}

Table 2: Mean of social support score

\begin{tabular}{lcccl}
\hline & $\boldsymbol{M}$ & $\boldsymbol{S D}$ & $\boldsymbol{n}$ & \\
\hline overall & 3.33 & 1.37 & 90 & \\
male & 3.45 & 1.56 & 28 & $\mathrm{t}=0.54$ \\
female & 3.27 & 1.29 & 62 & $\mathrm{df}=88$ \\
$\mathrm{p}=0.59$
\end{tabular}

than two), subjective financial status (inadequate, adequate), employment (unemployed, employed) and psysical illness (absent, present).

There was a significat correlation $(R)$ of social support score with type of family, employment and physical illness. There was poor correlaton with other variables (Table 3 ).

Three models of regression analysis was done stepwise by the computer automatically adding the variable with significant correlation one at a time in each step until the change statistic in the model was

Table 3: Correlation between social support and variables

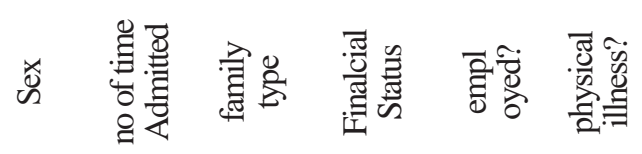

\begin{tabular}{lccccccc}
\hline social & $R$ & -.058 & -.045 & .378 & -.064 & .519 & -.408 \\
support & $p$ & .295 & .336 & .000 & .275 & .000 & .000 \\
& $p$ & & &
\end{tabular}


significat. The result is shown in Table 4. It shows three models with increasing $\mathrm{R}^{2}$ until the change in $\mathrm{R}^{2}$ is significant. Here, model 3 has the higest $\mathrm{R}^{2}$ indicating highest coffecient of determination of dependent variable taking into account the predictors in that model.

Table 4: Regression Model

\begin{tabular}{cccccc}
\hline Model & $\boldsymbol{R}$ & $\boldsymbol{R}^{\mathbf{2}}$ & $\begin{array}{c}\text { Adjusted } \\
\boldsymbol{R}^{\mathbf{2}}\end{array}$ & $\begin{array}{c}\boldsymbol{R}^{\mathbf{2}} \\
\text { Change }\end{array}$ & $\boldsymbol{p}$ \\
\hline $\mathbf{1}$ & $.519^{\mathrm{a}}$ & .269 & .261 & .269 & .000 \\
$\mathbf{2}$ & $.696^{\mathrm{b}}$ & .484 & .472 & .215 & .000 \\
$\mathbf{3}$ & $.749^{\mathrm{c}}$ & .561 & .546 & .077 & .000 \\
\hline
\end{tabular}

a. Predictors: (Constant), employed

b. Predictors: (Constant), employed, Type of family

c. Predictors: (Constant), employed, Type of family, physical illness

Dependent Variable: PSS_score

Table 5 shows the regression coefficients of the predictors. Social support score (sss) can be predicted as:

$$
\text { sss }=28.4+20.06(\text { employment })+13.48(\text { family }
$$$$
\text { type) - 9.77(physical illness) }
$$

where employment $=1$ if employed and

$$
0 \text { if unemployed, and }
$$

family type $=1$ if joint and 0 if nuclear, physical illness $=1$ if present and 0 if none.

Employment status, when adjusted for other variables, has the greatest influence on the support score as shown by the largest Beta value. Type of family has lesser influence and physical illness has least influence in the opposite direction, i.e. if physical illness occurs, the social support score decreases.

Table 5: Regression coefficients

\begin{tabular}{lcccc}
\hline & $\begin{array}{c}\text { Unstandardized } \\
\text { Coefficients }\end{array}$ & $\begin{array}{l}\text { Standardized } \\
\text { Coefficients }\end{array}$ & \\
\hline & $B$ & Std. Error & Beta & $p$ \\
(Constant) & 28.402 & 2.929 & & .000 \\
employed & 20.056 & 2.515 & .577 & .000 \\
$\begin{array}{l}\text { Type of } \\
\text { family }\end{array}$ & 13.481 & 2.718 & .377 & .000 \\
$\begin{array}{l}\text { physical } \\
\text { illness }\end{array}$ & -9.769 & 2.512 & -.292 & .000 \\
\hline
\end{tabular}

\section{DISCUSSION:}

The majority $(60 \%)$ of the patient perceived social support from family, $28 \%$ from significant others and the rest $12 \%$ from friends. Other studies also has similar findings and states that support from family and friends is a key part for people with mental illness. ${ }^{8}$ Close relations like spouse/partner or parent are better support system for mentally ill patients. Social support, particularly the emotional support from a close relatives is one important protective factor for mental health problems. Support from significant others included siblings and peers was also the crucial system to provide support, and their relationships should be encouraged as an important part of service delivery to families dealing with mental illness. ${ }^{9}$

This study shows that the patients who were employed had significantly better perceived social support than the unemployed. Similarly, patient staying with the joint family had better support. Those with physical illness had negative support. These finding are supported by other studies that if mentally ill people were unemployed or stay in a nuclear family, they got less support from other resources too. ${ }^{10,11}$ This might be due to the fact that the families of mentally ill patients comes under financial strain to support them along with financial hardship, which is indicated by lack of material resources and inability to afford essentials.

There is no significant relationship of social support with gender, subjective financial status, number of times hospitalized.

\section{CONCLUSION:}

Perceived social support is significantly better in employed people and in those who live in joint family. Support is significantly less if one has physical illness. Social support is not influenced by gender, subjective financial status and number of times hospitalized.

Conflict of interest: None.

Financial declaration: None 


\section{REFERENCES:}

1. Attkisson C, Cook J, Karno M, Lehman A, McGlashan TH, O'Connor M, et al. Clinical services research. Schizophrenia Bulletin. 1992;18(4):561-626.

2. Hoenig J, Hamilton MW. The schizophrenic patient in the community and his effect on the household. International Journal of Social Psychiatry. 1966;12(3):165-76.

3. Tonsing K, Zimet GD, Tse S. Assessing social support among South Asians: The multidimensional scale of perceived social support. Asian Journal of Psychiatry. 2012;5(2):164-8.

4. Zimet GD, Powell SS, Farley GK, Werkman S, Berkoff KA. Psychometric characteristics of the Multidimensional Scale of Perceived Social support. Journal of Personality Assess. 1990;55(3-4):610-17.

5. Edwards LM. Measuring perceived social support in Mexican American Youth: Psychometric properties of the multidimensional scale of perceived social support. Hispanic journal of behavioral sciences. 2004;26(2):187-94.

6. Association of Relatives and Friends of the Emotionally and Mentally Ill. (2007). Identifying carer needs for support and advocacy (ARAFEMI Carer Consultation: Research Report 1). Retrieved 25 April 2014, from http:// www.arafemi.org.au/uploads/downloads/CarerConsultationFinalReport2.pdf.
7. Baronet AM. Factors associated with caregiver burden in mental illness: A critical review of the research literature. Clinical Psychology Review. 1999;19(7):819-41.

8. Edwards B, Higgins D, Gray M, Zmijewski N, Kingston $\mathrm{M}$. The nature and impact of caring for family members with a disability in Australia (Research Report No. 16). Melbourne: Australian Institute of Family Studies, 2008.

9. McCabe KM, Yeh M, Lau A, Garland A Hough R. Racial/ ethnic differences in caregiver strain and perceived social support among parents of youth with emotional and behavioral problems. Ment Health Serv Res. 2003;5(3):137-47.

10. Guarnaccia PJ, Parra P. Ethnicity, social status, and families' experiences of caring for a mentally ill family member. Community Mental Health Journal. 1996;32(3):24360.

11. Reupert A, Maybery D. Families affected by parental mental illness: Australian programs, strategies and issues. The (missing) role of schools. International Journal for SchoolBased Family Counseling. 2010;2:1-16.

12. Zimet GD, Dahlem NW, Walker RR. The multidimensional scale of perceived social support: A confirmation study. Journal of clinical psychology. 1991;47(6):756-61. 